\title{
Iron deficiency anemia and Plummer-Vinson syndrome: current insights
}

\author{
This article was published in the following Dove Press journal: \\ Journal of Blood Medicine \\ 19 October 2017 \\ Number of times this article has been viewed
}

\author{
Amit Goel' \\ Satvinder Singh Bakshi \\ Neetu Soni ${ }^{3}$ \\ Nanda Chhavi ${ }^{4}$ \\ 'Department of Gastroenterology, \\ Sanjay Gandhi Postgraduate Institute \\ of Medical Sciences, Lucknow, India; \\ ${ }^{2}$ Department of Otorhinolaryngology \\ and Head and Neck Surgery, \\ Mahatma Gandhi Medical College \\ and Research Institute, Puducherry, \\ India; ${ }^{3}$ Department of Radiodiagnosis, \\ Sanjay Gandhi Postgraduate Institute \\ of Medical Sciences, Lucknow, India; \\ ${ }^{4}$ Department of Pediatrics, Era's \\ Lucknow Medical College, Lucknow, \\ India
}

Correspondence: Amit Goel

Department of Gastroenterology, Sanjay Gandhi Postgraduate Institute of Medical Sciences (SGPGI), Rae Bareli Road,

Lucknow 2260I4, India

Tel +9l 5222495549

Email agoel.ag@gmail.com
Abstract: Plummer-Vinson syndrome (PVS), a rare clinical condition, is characterized by a triad of dysphagia, iron deficiency anemia and esophageal web in the post-cricoid region. It was first described over a century ago. However, literature on this condition remains scanty, and its prevalence appears to be declining worldwide, possibly due to improvements in nutrition over time. The condition has been reported most commonly in thin-built, middle-aged, white women. The esophageal webs in PVS are thin mucosal folds, which are best seen either in lateral views at barium swallow or at esophagoscopy. These are usually semilunar or crescentic, being located most often along the anterior esophageal wall, but can be concentric. The exact cause and pathogenesis of PVS remain unclear, though iron and other nutritional deficiencies, genetic predisposition and autoimmunity have all been implicated in formation of the webs. Treatment includes correction of iron deficiency and endoscopic dilation of the esophageal webs to relieve dysphagia. PVS is associated with an increased risk of hypopharyngeal and esophageal malignancies. Correction of iron deficiency may arrest and reverse the mucosal changes and possibly reduces this risk.

Keywords: Plummer-Vinson syndrome, Paterson-Brown-Kelly syndrome, esophageal web, dysphagia, iron deficiency anemia

\section{Introduction}

Difficulty in swallowing or dysphagia is a common symptom. Esophageal webs are an infrequent cause of dysphagia. These have been found to occur in association with iron deficiency anemia (IDA) and dysphagia. This clinical triad - of IDA, esophageal web and dysphagia - has been named variously as "Plummer-Vinson syndrome" (PVS; primarily in the USA) and as "Paterson-Brown-Kelly syndrome" (used primarily in the UK). ${ }^{1}$ The former term was derived from the names of two physicians - Henry Stanley Plummer and Porter Paisley Vinson, at the Mayo Clinic - who separately described this condition and speculated that "cardiospasm"2 and "angulation"3 of the esophagus, respectively, were responsible for the dysphagia. Around the same time, two laryngologists from Britain, Donald Ross Paterson and Adam Brown-Kelly, provided detailed clinical descriptions of this condition and also noticed its association with anemia and post-cricoid webs, ${ }^{4,5}$ helping establish this entity as an independent syndrome, a contribution recognized by the name "Paterson-Brown-Kelly syndrome". This review uses the term PVS throughout because of its somewhat more frequent use in the recent published literature.

PVS is a rare condition that continues to be enigmatic, even though a century has passed since its first description. ${ }^{2}$ The literature available on its pathogenesis, treatment 
and natural history is limited to case reports, retrospective short case series and a few large series. ${ }^{6,7}$ In this review, we have attempted to collate the available information on PVS.

\section{Epidemiology}

It is interesting to note that, after passage of a century since its first description, literature on PVS is still restricted to case reports and small case series. ${ }^{8-10} \mathrm{PVS}$ has been reported from all parts of the world. In the initial decades after its description, several reports of PVS emerged from Europe ${ }^{11-14}$ and North America, ${ }^{15-17}$ reflecting its increasing recognition in the areas from where it was first described. However, with economic growth and improvement in nutrition in these regions, the condition appears to have disappeared there. Instead, in the last few decades, PVS has been increasingly recognized in developing countries of Asia, with most of the reports coming from this continent. ${ }^{8,18-21}$ The sharp decline in reports on PVS from the developed world has temporally coincided with the disappearance of iron deficiency, because of combined effects of improved nutritional status and hygiene, reduced worm infestation, iron supplementation and fortification of dietary substances with iron. ${ }^{22}$ Interestingly, despite a high prevalence of IDA in Africa, PVS has rarely been reported there, though this may reflect the low contribution of this continent to the published medical literature. ${ }^{10,20,23}$

PVS is a rare condition, and the data on its incidence or prevalence rate are limited to a single population-based study conducted in South Wales in early 1960s. ${ }^{14}$ In this study, 1994 men and 2346 women were screened for post-cricoid dysphagia using a questionnaire followed by a barium study in those reporting symptoms. The prevalence of post-cricoid webs was found to be $0.3 \%-1.1 \%$ and $8.4 \%-22.4 \%$ among women overall and in women with dysphagia, respectively. None of the men were found to have a post-cricoid web. ${ }^{14}$

In a large radiologic study from New York, 1000 consecutive cineradiographs of the hypopharynx and cervical esophagus were examined, and esophagus webs were found in $5.5 \%$ of these. However, of the 55 patients with webs, only 6 had dysphagia attributable to these webs, and none met the criteria for PVS. ${ }^{24}$

\section{Etiology}

The exact cause for PVS and of web formation remains unknown. Several hypotheses have been proposed to explain their pathogenesis, each supported by relatively weak evidence, consisting primarily of the clinical associations of esophageal webs and PVS with other systemic illnesses. The proposed causative mechanisms have included IDA, malnutrition, genetic predisposition, autoimmune processes and other dietary deficiencies (such as of pyridoxine or riboflavin).

\section{Iron deficiency anemia}

IDA is the most extensively studied and currently the most widely accepted causative association of PVS. The assumed role of IDA in the formation of esophageal webs is based primarily on: 1) its common association with such webs in patients with PVS, 2) a high prevalence of IDA in patients with post-cricoid dysphagia, 3) reports of improvement in dysphagia and disappearance of esophageal $\mathrm{web}^{25}$ and associated esophageal motility disturbances following iron therapy, ${ }^{26,27}$ and 4) the presence of risk factors for IDA, such as post-gastrectomy status, atrophic gastritis, achlorhydria and female gender, in patients with esophageal webs. ${ }^{28}$

However, the IDA hypothesis fails to explain several observations, namely, the occurrence of webs in some patients in the absence of IDA, ${ }^{29}$ lack of concordance between the geographic distribution of IDA and esophageal webs, rarity of web formation despite a high prevalence of IDA in African populations, poor association of severity of IDA with the severity of dysphagia, the exclusive post-cricoid location of esophagus webs in patients with IDA, and the failure to induce similar lesions in animal models with iron deficiency. ${ }^{30}$

Thus, though the current knowledge suggests a central role for IDA in predisposing the post-cricoid mucosa to web formation, it does not appear to be adequate by itself and appears to require the presence of some additional factors. Further information on the role of iron in the formation of post-cricoid webs is available in an excellent review on the subject, albeit published several years ago. ${ }^{30}$

\section{Other nutritional deficiencies}

Deficiencies of some B vitamins, such as riboflavin, thiamine and pyridoxine, have been proposed as a cause for PVS, though the evidence for this is weak and inconclusive. Mucosal changes in the oropharynx, such as stomatitis, atrophy of the lingual epithelium, loss of lingual papillae and angular cheilosis, have been described in persons with riboflavin and pyridoxine deficiencies, and can be induced experimentally in animal models. Frequent occurrence of dysphagia, hypopharyngeal and oral cancers has been described among women from remote rural areas in northern Sweden, where vitamin deficiencies were common, because of long winter seasons and consequent poor supply of fresh vegetables, meat and fish. ${ }^{31}$ Riboflavin also plays a key role in several steps during erythropoiesis, including iron absorption and mobilization 
of ferritin from tissues, and its deficiency could thus contribute to anemia. ${ }^{32}$ However, Jacobs and Cavill reported that riboflavin content of the red blood cells was normal in 25 PVS patients, and was comparable between anemic and non-anemic patients. ${ }^{33}$

\section{Autoimmunity}

Host's immune response against a self-antigen, which is yet unrecognized, has also been proposed as playing a role in the formation of esophageal web. This hypothesis is based on reports highlighting the association of PVS with autoimmune disease. ${ }^{28,34,35}$ Celiac disease, an autoimmune condition, can present as refractory IDA and can be considered as an etiologic factor in PVS. ${ }^{20,36-38}$ Abnormally high prevalence of overt and latent pernicious anemia is reported in patients with IDA. ${ }^{39,40}$ In addition, cases of PVS with thyroiditis, rheumatoid arthritis ${ }^{41}$ or Crohn's disease ${ }^{18}$ have also been reported. Furthermore, there is evidence to support an autoimmune mechanism for mucosal changes of atrophic gastritis in patients with iron deficiency. ${ }^{42}$

\section{Pathogenesis}

The exact pathogenesis of PVS or formation of esophageal web is unclear, partly because such studies are difficult to conduct due to the infrequent nature of this condition. Several hypotheses have been put forward to explain the pathogenesis of web formation and its peculiar location, ${ }^{43}$ though IDA is the only factor that is unanimously accepted to play a role.

Iron is an important element for normal body homeostasis. It is essential for hemoglobin and myoglobin synthesis and also acts as a cofactor for several enzymes involved in cellular metabolism. The origin of esophageal web is proposed to be related to a reduction in the activity of irondependent oxidative enzymes, secondary to iron deficiency. This results in gradual degradation of the pharyngeal muscles and atrophy of the mucosa overlying them, leading to the development of webs. ${ }^{44}$ This hypothesis is supported by evidence from a histochemical study of thyropharyngeal, cricopharyngeal and cervical esophageal muscles from rabbits with IDA, which showed mitochondrial damage, with a "moth eaten" appearance, in type I muscle fibers. These changes were similar to those observed in muscles of patients with progressive muscular dystrophy. ${ }^{45}$ These losses of iron-dependent enzymes are further aggravated because of the high turnover of gastrointestinal tract epithelial lining. However, this theory fails to explain the localization of webs exclusively in the upper esophagus, which is lined with a stratified squamous epithelium which has a relatively slower turnover, rather than in rapidly renewing mucosa located in the small or large intestine.

IDA is associated with degeneration and atrophy of the epithelial lining of the tongue, hypopharynx and stomach, though there is no correlation between the severity of these epithelial changes and the severity and duration of IDA. Detailed histologic examination reveals epithelial atrophy, often with subepithelial round cell infiltration, parakeratosis or abnormal keratinization, and reduced levels of glycogen and cytochrome oxidase in the prickle cells.

The unhealthy mucosa in the hypopharynx elicits a chronic, low-grade inflammation leading to submucosal fibrosis which may extend into the surrounding pharyngeal muscles. These mucosal changes probably occur throughout the esophagus, but manifest in only the post-cricoid region which faces the maximal trauma during swallowing of solid bolus. The risk for trauma in this region is further increased because it is bound, both anteriorly and posteriorly, by skeletal elements. As the cricoid cartilage moves upward during swallowing, the mucosa on its posterior aspect is drawn over the descending food bolus, leading to trauma and web formation. ${ }^{46}$

An alternative explanation for the specific location of the web is the possible existence in some people of a band of ectopic gastric mucosa in the upper esophagus, acid secretion from which causes local inflammation and stricture (web) formation. However, this hypothesis fails to explain the nonexistence of webs in the lower esophagus, which is more frequently and more intensely exposed to gastric acid. ${ }^{16}$ Furthermore, the inflammatory origin of the web fails to explain the thin, film-like nature of the web.

Abnormal movement of muscles in pharynx and esophagus has also been implicated in web formation. Anemia may cause decreased esophageal motility, possibly through impaired mitochondrial function and/or low neuronal nitric oxide synthetase activity. Impaired heme synthesis, seen in IDA, may induce mitochondrial DNA damage and cause a functional defect in these organelles by a poorly understood mechanism. Mitochondrial impairment has been linked to cancer, aging and most neurodegenerative diseases such as web formation.

A detailed radiographic swallowing study of PVS has shown that the anterior wall of the upper esophagus in these patients fails to dilate following liquid bolus, thereby forming a fold, which gives the impression of a web on esophagography. ${ }^{45}$ Another study showed reduced esophageal motility in patients with IDA without esophageal web, which improved with iron supplementation. ${ }^{27}$ In a prospective comparison 
of oropharyngeal and esophageal transit and esophageal motility between IDA patients and healthy volunteers, the former group showed a slower esophageal transit, with shorter duration and lower amplitude of esophageal contractions, particularly in the upper and middle esophagus, that is, the location of the web. ${ }^{47}$

Overall, it appears that several factors such as iron deficiency, mucosal inflammation and atrophy, muscle degeneration, food bolus-induced trauma and esophageal dysmotility contribute to the web formation in PVS, though the absolute and relative contribution of each factor remains elusive.

\section{Morphology of esophageal webs}

Esophageal webs are thin, shelf-like, circular or semi-circular, pink-whitish, membranous structures consisting of two layers of mucosa and scanty fibrous tissue sandwiched between them, but without any muscular tissue. These are located exclusively in the upper esophagus, usually just below the upper esophageal sphincter. This location makes it difficult to obtain a biopsy of a web.

In the limited histologic data available, the webs in patients with PVS are characterized by fibrosis, epithelial atrophy, epithelial hyperplasia and hyperkeratosis, basal cell hyperplasia and irregularities, combined occasionally with features of chronic inflammation. Overall, the histologic appearance is that of a fold of normal esophageal epithelium with some underlying loose connective tissue. ${ }^{48}$ In a few patients, precancerous epithelial changes have also been noted. Subepithelium shows infiltration with round cells. Similar histologic changes have been described in buccal mucosa in patients with IDA. ${ }^{49}$

\section{Clinical features}

In large clinical series and a population-based study, the majority of patients were middle aged. ${ }^{6,14,50}$ PVS has also rarely been reported in children and adolescents. ${ }^{12,13,51}$ The average age of patients with post-cricoid carcinoma is about 15 years older than that of patients with PVS. ${ }^{52}$ Whites appear to be affected more often than the black population groups. Women are affected much more often than men, such that, at one point of time, PVS was considered to be a disease exclusively of women. Two large studies have shown female-to-male ratio of $\sim 8.5: 1{ }^{6,7}$ This striking female preponderance may be attributable at least partly to a higher prevalence of IDA among women, because of lower dietary intake, menstrual blood loss and pregnancy.

The typical triad of PVS is not seen in all patients with esophageal web. Dysphagia and IDA are the most common presenting features, and some patients do not have a clearly demonstrable web. Similarly, all the patients with IDA and esophageal web do not have dysphagia.

The dysphagia in PVS has a gradual onset, and is usually painless and intermittent. Patients usually point to the neck at or above the suprasternal notch as the site of obstruction. Dysphagia is usually noticed first for solid foods, which is then followed after several years by difficulty in swallowing liquids, suggesting an extremely slow progression of the esophageal obstruction. The patients tend to circumvent the symptom by either modifying the diet or consuming softer solids, and/or by enhanced chewing to break the food into smaller particles. Thus, there is often an interval of several years between the onset of dysphagia and the patient seeking medical attention. ${ }^{53}$ The obstruction may result in the person taking longer to complete a meal. With worsening obstruction, choking and/or episodes of aspiration may occur.

Dysphagia manifests only when the luminal diameter in the region of the web becomes $<12 \mathrm{~mm}$. Two recent reports of PVS, which graded severity of dysphagia using this system, showed that nearly $80 \%$ of the symptomatic patients with PVS had grade I (occasional dysphagia on taking solid foods) or II (able to swallow only semi-solid diet) dysphagia;, ${ }^{6,55}$ more severe grades of dysphagia (grade III: able to swallow only liquid diet, or grade IV: inability to take even liquids in adequate amount) were infrequent. ${ }^{54}$

Anemia can manifest with several symptoms, such as easy fatigability, exertional dyspnea, weakness, palpitations and so on, and any one or a combination of these symptoms may bring the patient to the physician. Physical examination reveals pallor.

IDA may be associated with deficiencies of other nutrients, in particular, vitamins, which could manifest as soreness of mouth, glossitis, angular cheilitis, atrophic glossitis (Figure 1), premature loss of teeth, koilonychia (spoonshaped finger nails), clubbing, seborrheic dermatitis, hyperkeratosis, conjunctivitis, keratitis, blepharitis, paresthesia and/or night blindness. Occasionally, women may experience complaints of burning and itching in the vulval region, which disappears after iron treatment, suggesting involvement of genital mucosa with epithelial lesions similar to those in the mouth and throat.

Occasionally, PVS may be associated with other conditions, such as an autoimmune disease, celiac disease, malignancy and so on. In such cases, the symptoms of these associated conditions may predominate over the longstanding mild dysphagia or well-tolerated anemia. 


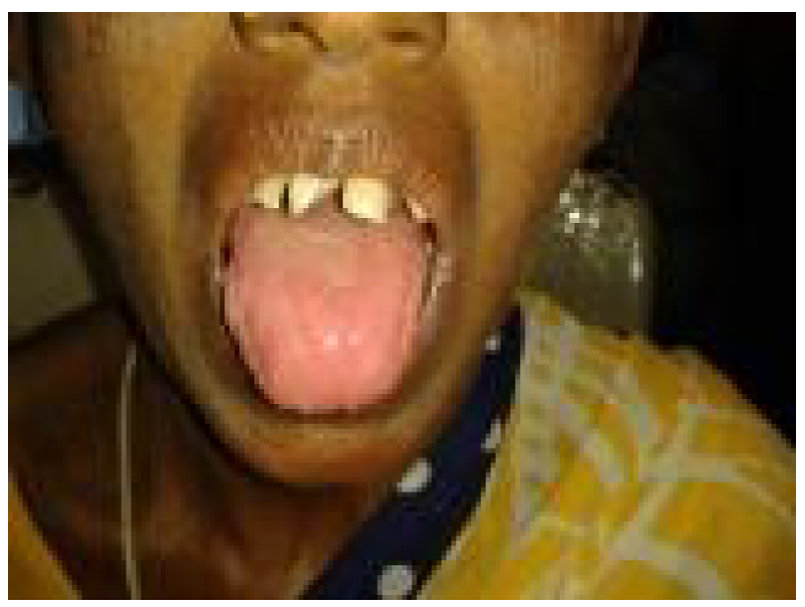

Figure I Picture showing glossitis and angular cheilosis.

\section{Laboratory investigations}

The objectives of investigations in a patient with suspected esophageal web or PVS are: to diagnose anemia, ascertain the cause of anemia, assess the severity and cause of dysphagia and to localize the obstructing lesion to help plan definitive treatment. Hence, the investigations include hematologic tests, and radiographic (barium swallow) and endoscopic examinations of the esophagus. In some patients, further investigations may be required to identify associated conditions such as thyroid disorders, celiac disease and so on to exclude hypopharyngeal or esophageal malignancy and to identify the cause for IDA, such as looking for occult blood loss, endoscopic examination to look for lesions in the distal gastrointestinal tract and investigations to look for the cause of blood loss from the female genital tract and so on.

\section{Hematologic tests}

Hemoglobin concentration in blood, microscopic examination of peripheral blood smear, red cell indices (mean corpuscular volume, mean corpuscular hemoglobin and mean corpuscular hemoglobin concentration) and serum iron studies (serum iron, ferritin and total iron binding capacity) are helpful in diagnosing the presence or absence of anemia and to establish iron deficiency as its cause. According to the World Health Organization, a hemoglobin level of $<12$ $\mathrm{g} / \mathrm{dL}$ in nonpregnant women or $<13 \mathrm{~g} / \mathrm{dL}$ in men is used to define anemia. Iron deficiency is considered as the cause for anemia in the presence of microcytic hypochromic picture on peripheral blood smear examination, serum ferritin level $<30 \mu \mathrm{g} / \mathrm{L}$ and mean corpuscular volume $<80 \mathrm{fL}$. IDA can be caused either by poor intake of iron or excessive loss of body iron. If poor intake or genital blood loss is not considered likely, investigations to look for the presence and cause of blood loss from the gastrointestinal tract are needed.

\section{Radiography of the esophagus}

Barium swallow radiography is the investigation most commonly asked for if an esophageal web is suspected. It has a few advantages over endoscopic examination. Besides being time-honored, it is more easily available in remote locations and can be interpreted by a radiologist or a clinician with no special skill or training. Further, it helps to differentiate between benign and malignant causes of obstruction, planning of definitive treatment, and provides a reproducible documentation of pretreatment status for comparison after treatment or other later use. ${ }^{56}$

Occasionally, the information provided by conventional barium swallow is either equivocal or negative and not commensurate with clinical suspicion. Such patients need video cineradiography and/or video fluoroscopy, which provide a dynamic X-ray evaluation of the process of swallowing, as the barium bolus moves from the mouth to the esophagus. ${ }^{57}$ These techniques can identify smaller webs and can better distinguish true webs from false webs formed by mucosal folds or extrinsic pressure. However, these are not easily available, particularly in developing countries where PVS is common.

To obtain the maximum information from barium swallow or cineradiography, a few precautions are in order. These include the use of a large bolus of thick barium and acquisition of lateral view images in standing position. In these images, a web would appear as a thin projection in the post-cricoid region or in the upper esophagus, with a dilated proximal segment and a normal or relatively narrowed distal segment. ${ }^{58-60}$ The webs are most commonly located on the anterior wall of the esophagus (Figure 2A), but can be located occasionally on the posterior wall (Figure 2B). Less frequently, they are circumferential (Figure 2C), with either a centrally placed or eccentrically placed opening. Though usually solitary, webs can also be multiple. ${ }^{6}$

Webs need to be differentiated from other benign or malignant causes of pharyngeal dysphagia, ${ }^{56}$ such as pharyngeal pouches or diverticula, Zenker's diverticula, idiopathic esophageal stricture, benign or malignant tumors or extrinsic compression of esophagus. Esophageal strictures can be distinguished from webs by demonstration of restricted distensibility of the neighboring esophageal wall, secondary to inflammation and fibrosis.

Forceful propulsion of barium through a relatively narrow opening of the web often produces a "jet phenomenon". 

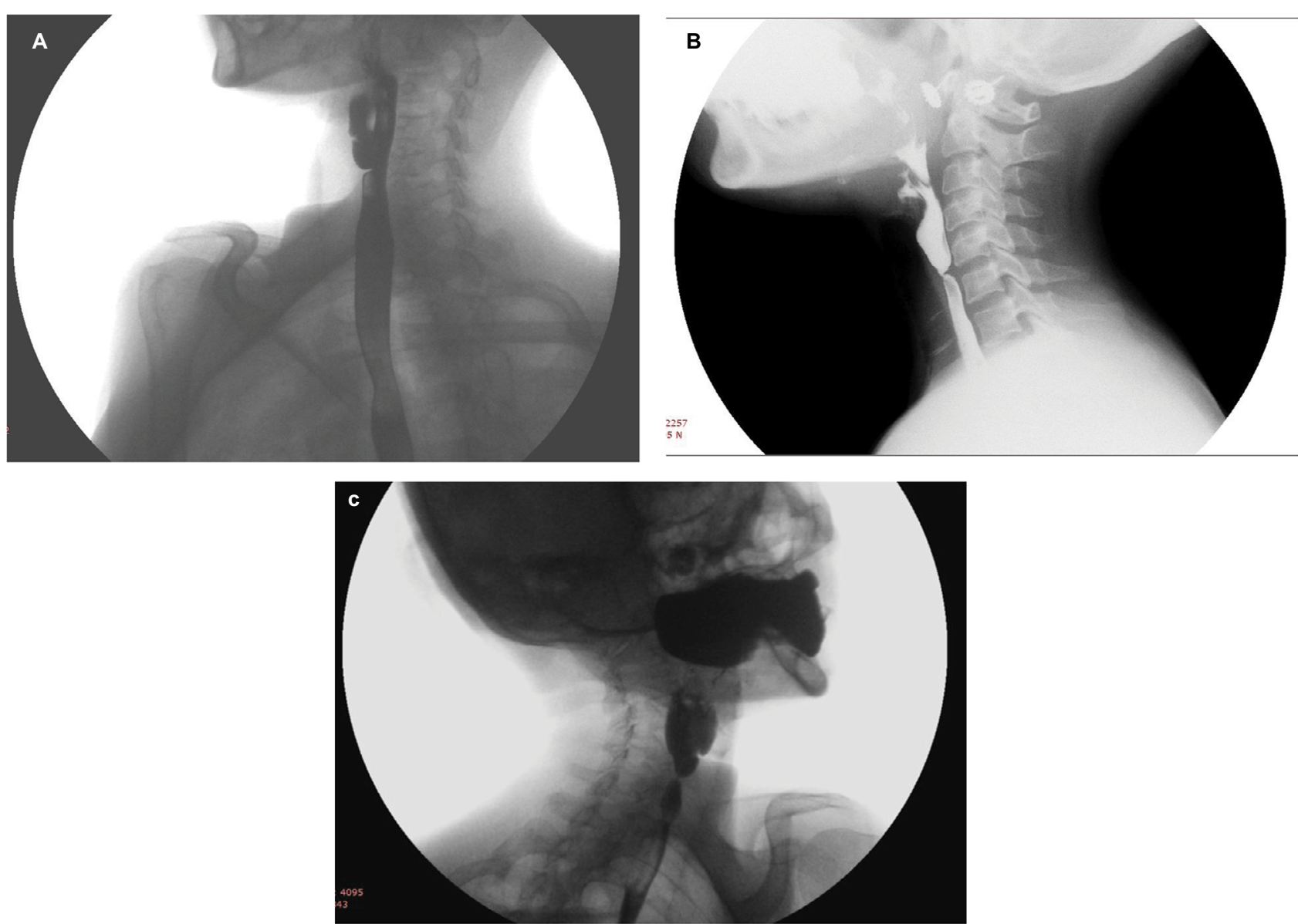

Figure $\mathbf{2}$ Lateral view of barium swallow study showing esophageal web on $(\mathbf{A})$ anterior wall, (B) posterior wall, and (C) a circumferential web.

Width of the jet immediately below the level of the web indicates the degree of narrowing (Figure 3). Sometimes, the web cannot be seen and its possibility is considered only because the jet phenomenon is observed; though infrequent, presence of this sign is fairly diagnostic of a web ${ }^{61}$ Its presence suggests a critical narrowing, and hence, patients with it are more likely to be symptomatic. In a recent prospective study, $86 \%$ of the esophageal webs were diagnosed by barium swallow and most of these webs showed jet phenomenon and poor lumen distensibility below the web. ${ }^{6}$

\section{Video endoscopy}

Fiber-optic endoscopy is a safe and reliable tool for examining gastrointestinal tract. Endoscopic examination of the esophagus is called esophagoscopy. Esophagoscopy has the advantage of permitting treatment in the same sitting. In patients suspected to have an esophageal web, endoscopic examination has to be performed very cautiously, preferably under anesthesia or sedation. These webs are very thin and are located very close to the upper esophageal sphincter in the esophagus, an area which is traversed very fast and, hence, is

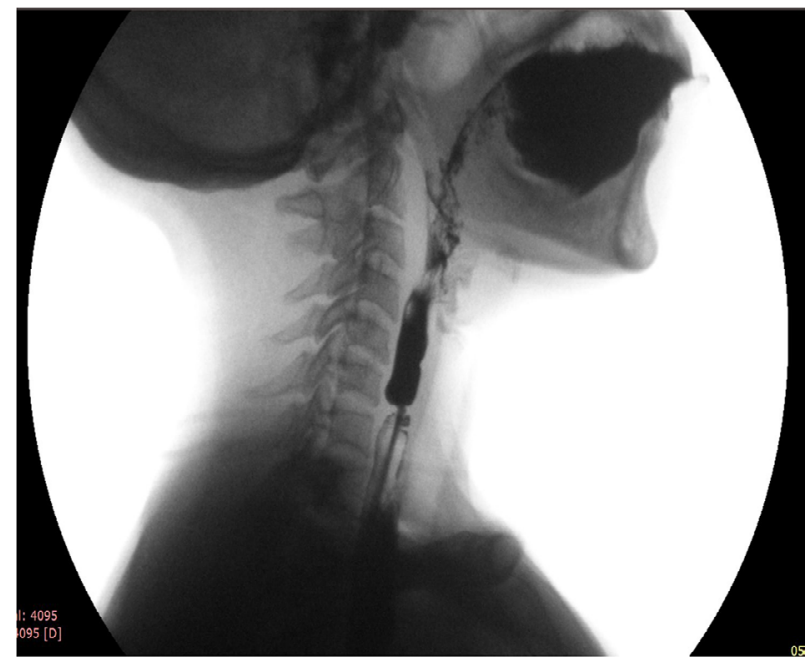

Figure 3 Lateral view of barium swallow study in a patient with circumferential web with severe narrowing producing "jet phenomenon" below the level of narrowing because of the web.

often not evaluated well during esophagoscopy (Figure 4A, B). Hence, if the endoscopist is not aware or informed of the esophageal web, he/she may rupture it during the passage of the endoscope. Such an unintended rupture of a web will 


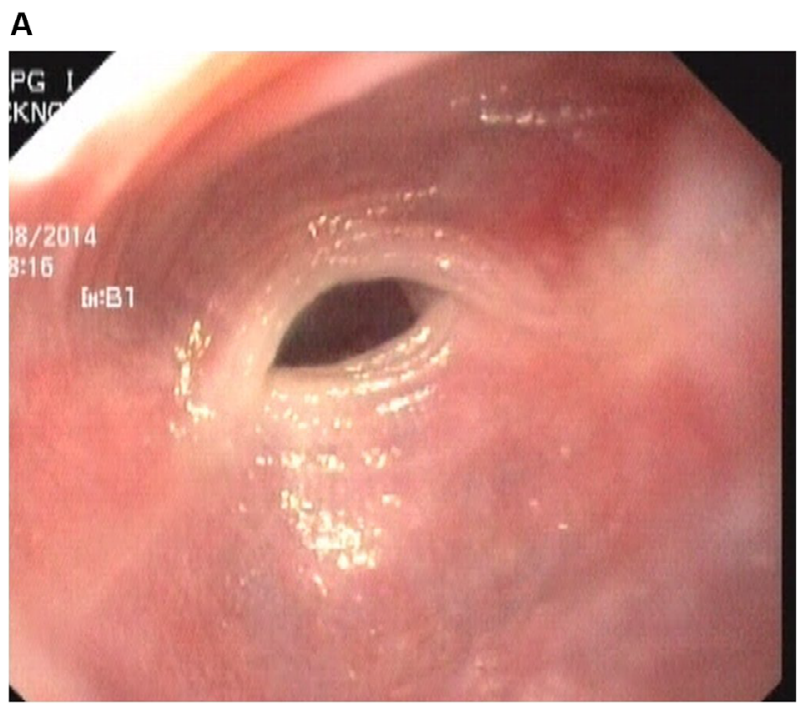

B

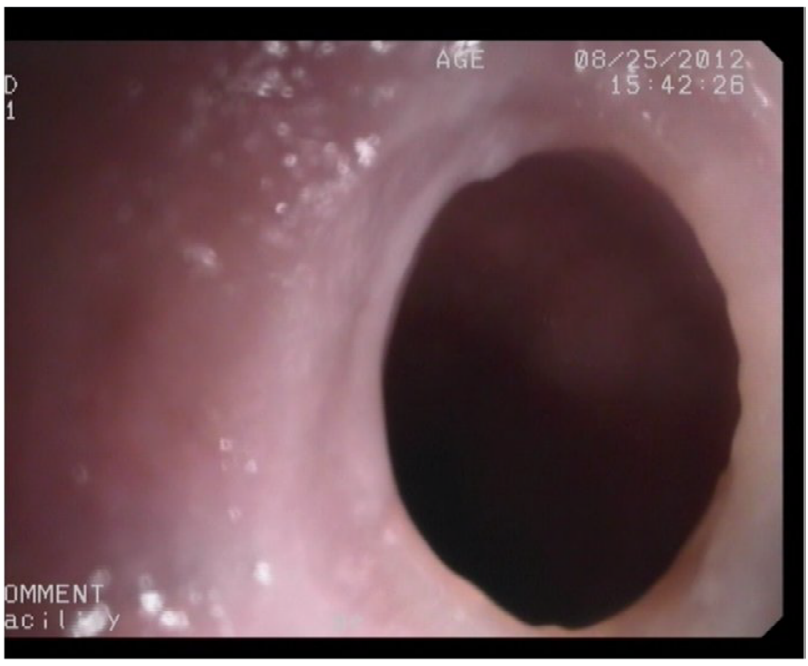

Figure 4 Endoscopic view of upper esophagus showing webs: (A) semilunar or crescent, and (B) circumferential.

produce a small amount of bleeding at the site of esophageal web, which could be misinterpreted, by the endoscopist, as mucosal irregularity due to esophageal carcinoma. Confusing a benign pathology with a malignant one will result in a trail of unnecessary investigations and follow-up, leading to unnecessary financial burden and psychologic stress.

At endoscopy, the webs appear as smooth, thin, gray lesions with eccentric or central lumen and normal-appearing mucosa. Careful examination of the remaining esophagus and the stomach is essential to exclude the presence of a malignancy, since PVS has been considered as a precancerous condition. Furthermore, the examination of stomach and duodenum may identify a cause for IDA.

\section{Differential diagnosis}

It is important to distinguish PVS from other causes of dysphagia. It must be remembered that causes of dysphagia other than PVS are much more common, and hence, mere presence of IDA or a web should not lead to the diagnosis of PVS. The benign causes which need consideration include vascular rings, pharyngeal pouch and diverticulum, esophageal strictures secondary to corrosive injury, surgical anastomosis in the esophagus specifically following surgery for tracheoesophageal fistula in the neonatal period, esophageal strictures following esophageal injury (blunt trauma, penetrating injuries), compression effects, gastroesophageal reflux disease and idiopathic stricture. Esophageal motility disorders such as scleroderma, achalasia cardia, diffuse esophageal spasm and nutcracker esophagus can also present with dysphagia, and the web may be an incidental finding. In addition, benign and malignant tumors of the esophagus and retained foreign bodies in the pharynx or esophagus should be considered, particularly in those at the extreme of ages.

\section{Treatment}

Patients with PVS need treatment for IDA as well as for dysphagia.

\section{Iron deficiency anemia}

An important first step in the management of IDA is to exclude occult or overt blood loss from any source, such as menstrual bleeding, gastrointestinal tract malignancy, worm infestation and so on, or iron malabsorption, for example, celiac disease. In the majority of patients with PVS, the iron deficiency is nutritional and can be treated easily with iron supplementation, either oral or parenteral. Several recent excellent reviews are available on iron therapy ${ }^{62-64}$ and may be consulted.

Iron supplementation alone resolves dysphagia in many patients. ${ }^{65,66}$ This treatment alone could be considered for those with mild dysphagia or if endoscopy facilities are not available. Advanced and long-standing dysphagia is unlikely to respond to iron replacement alone and requires dilatation of the web. Iron therapy should be considered in all patients with web, regardless of the hemoglobin status, to replenish the iron stores.

\section{Post-cricoid web}

Esophageal webs have been dilated using various endoscopic techniques, with the largest experience being with the use of endoscopic balloon dilatation ${ }^{6}$ or Savary-Gilliard dilators. ${ }^{7,67}$ Endoscopic laser division and electroincision have also been used successfully. ${ }^{19,68}$ Surgery is only rarely needed. 
Both endoscopic balloon and Savary-Gilliard dilators are used after anesthetizing the throat mucosa with xylocaine spray or syrup. Light sedation helps improve patient comfort and does not appear to increase the risk of complication. Dilatation is performed under fluoroscopic guidance after passing a guidewire into the stomach at endoscopy. Successful rupture of the web is recognized at endoscopy by the presence of a small amount of fresh blood at the location of the web (Figure 5A, B).

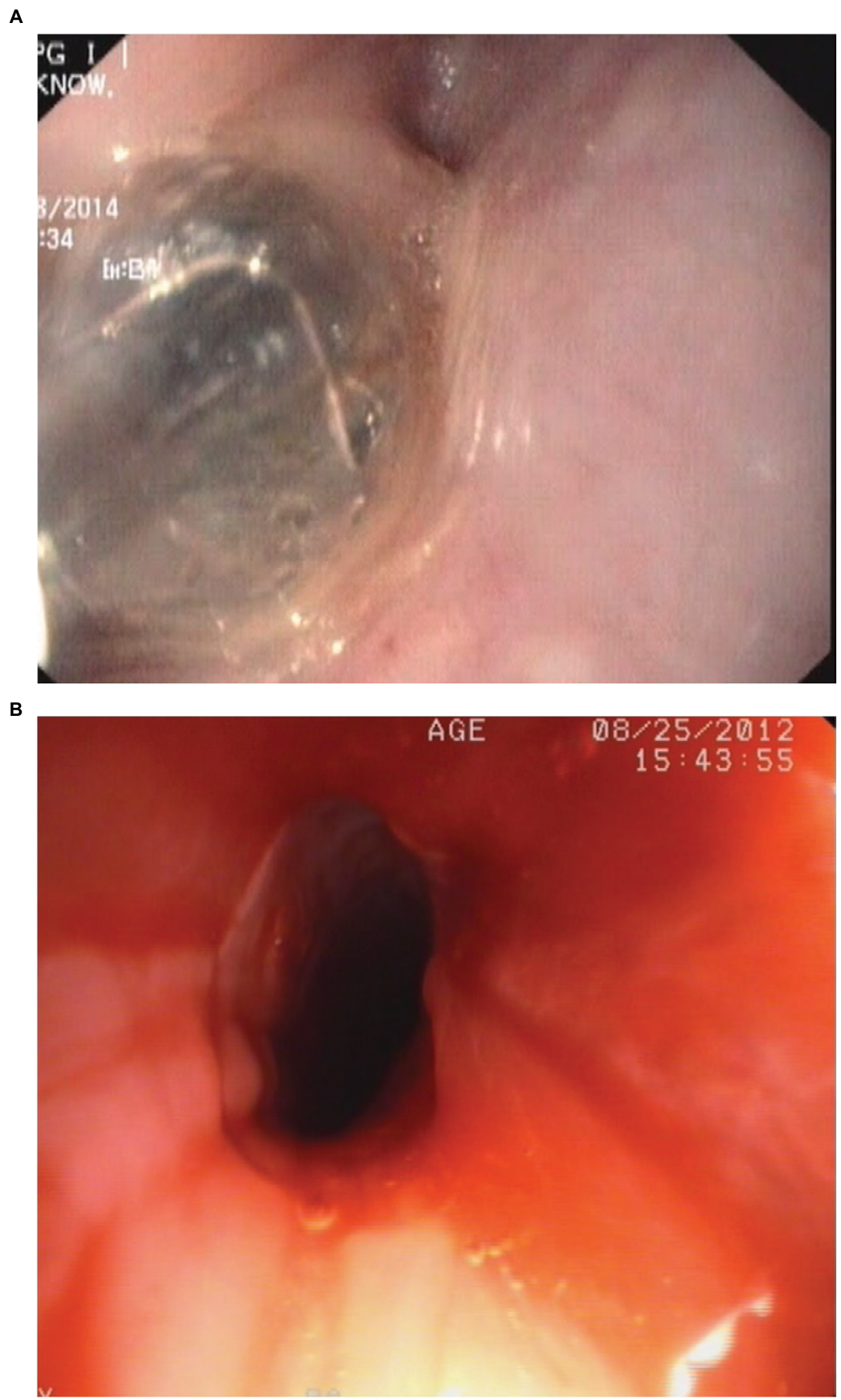

Figure 5 Endoscopic view of upper esophagus showing (A) balloon dilatation of web, and (B) fresh blood and remnants of circumferential web in the form of a rim after successful balloon dilatation. 
In a prospective study, a single session of balloon dilatation provided complete response in $94 \%$ of patients, with only some patients needing a repeat session. ${ }^{6}$ The recurrence of dysphagia is very uncommon. The rate of recurrence of dysphagia appears to be lower after endoscopic balloon dilatation than after Savary-Gilliard dilatation. ${ }^{6,7}$ Treatment of recurrence is easy and usually needs only a single session of dilatation.

\section{Prognosis}

Generally, patients with post-cricoid web or PVS have an excellent outcome. PVS is considered to be a precancerous state, and such patients are considered to be at risk of developing squamous cell carcinoma of the hypopharynx or upper esophagus.

In follow-up studies in patients with a post-cricoid web or PVS, post-cricoid carcinoma was observed in $4 \%-16 \%$ of patients. In a case series from Sweden, a high proportion of patients with hypopharyngeal carcinoma had preceding history of PVS. ${ }^{31}$ In recent case series of PVS, up to $10 \%$ of patients developed malignant transformation during followup. ${ }^{6,755}$ However, the exact mechanism for this is unknown. It is assumed that with long-standing iron deficiency, the atrophic mucosal changes become irreversible and, in some patients, progress to malignant degeneration. ${ }^{69}$

There are no formal guidelines for the follow-up of patients with PVS. Considering the malignant potential, it appears prudent that such patients are reassessed at least annually for the reappearance of dysphagia or other early indicators of malignancy. Further investigations such as barium swallow or endoscopy may be considered if the dysphagia recurs or any symptom suggestive of malignancy, such as anorexia, weight loss, odynophagia, change in voice or nasal regurgitation of food and water, appears.

\section{Conclusion and future directives}

Nearly a century after the first description of PVS, our knowledge of this condition is limited mostly to clinical features. The pathogenesis of web formation remains an enigma, though the introduction of therapeutic gastrointestinal endoscopy has improved the management of dysphagia. Our knowledge about the association of PVS with malignancies of the upper gastrointestinal tract also remains limited. In view of these and the infrequent nature of the disease, a protocol-based data collection and management of such patients is needed to help improve our understanding about this disease, including its pathogenesis, optimum treatment and natural history.

\section{Disclosure}

The authors report no conflicts of interest in this work.

\section{References}

1. Novacek G. Plummer-vinson syndrome. Orphanet $J$ Rare Dis. 2006;1:36.

2. Plummer H. Diffuse dilatation of the esophagus without anatomic stenosis (cardiospasm): a report of 91 cases. JAMA. 1912;58:2013-2015.

3. Vinson P. A case of cardiospasm with dilatation and angulation of the esophagus. Med Clin North Am. 1919;3:623-627.

4. Kelly A. Spasm at the entrance of the esophagus. J Laryngol Rhinol Otol. 1919;34:285-289.

5. Paterson D. Clinical type of dysphagia. J Laryngol Rhinol Otol. 1919;34:289-291.

6. Goel A, Lakshmi CP, Bakshi SS, Soni N, Koshy S. Single-center prospective study of Plummer-vinson syndrome. Dis Esophagus. 2016;29(7):837-841.

7. Bakari G, Benelbarhdadi I, Bahije L, El Feydi Essaid A. Endoscopic treatment of 135 cases of plummer-vinson web: a pilot experience. Gastrointest Endosc. 2014;80(4):738-741.

8. Bakshi SS. Plummer-vinson syndrome. Mayo Clin Proc. 2016;91:404

9. Masri O, Sharara AI. Plummer-vinson syndrome. Clin Gastroenterol Hepatol. 2013;11(12):e85.

10. Gude D, Bansal D, Malu A. Revisiting plummer vinson syndrome. Ann Med Health Sci Res. 2013;3(1):119-121.

11. Hutton CF. Plummer Vinson syndrome. Br J Radiol. 1956;29:81-85.

12. Crawfurd MD, Jacobs A, Murphy B, Peters DK. Paterson-kelly syndrome in adolescence. Br Med J. 1965;1:1189-1190.

13. Crawfurd MD, Jacobs A, Murphy B, Peters DK. Paterson-kelly syndrome in adolescence: a report of five cases. Br Med J. 1965;1(5436): 693-695.

14. Elwood PC, Jacobs A, Pitman RG, Entwistle CC. Epidemiology of the paterson-kelly syndrome. Lancet. 1964;2(7362):716-720.

15. Howell JT, Monto RW. Syndrome of anemia, dysphagia and glossitis (plummer vinson syndrome). N Engl J Med. 1953;249(25):1009-1012.

16. Weaver GA. Upper esophageal web due to a ring formed by a squamocolumnar junction with ectopic gastric mucosa (another explanation of the paterson-kelly, plummer-vinson syndrome). Dig Dis Sci. 1979;24(12):959-963.

17. Klifto EJ, Allen SK, Metzman M, Chase PJ, Kupersmit M. Plummervinson syndrome: report of a case and review of the literature. $J \mathrm{Am}$ Osteopath Assoc. 1983;83(1):56-59.

18. Park JM, Kim KO, Park CS, Jang BI. A case of plummer-vinson syndrome associated with crohn's disease. Korean $J$ Gastroenterol. 2014;63(4):244-247.

19. Ohtaka M, Kobayashi S, Yoshida T, et al. Use of sato's curved laryngoscope and an insulated-tip knife for endoscopic incisional therapy of esophageal web. Dig Endosc. 2015;27(4):522-526.

20. Hefaiedh R, Boutreaa Y, Ouakaa-Kchaou A, et al. Plummer vinson syndrome association with coeliac disease. Arab J Gastroenterol. 2013;14(4):183-185.

21. Hefaiedh R, Boutreaa Y, Ouakaa-Kchaou A, et al. Plummer-vinson syndrome. Tunis Med. 2010;88(10):721-724.

22. Chen TS, Chen PS. Rise and fall of the plummer-vinson syndrome. J Gastroenterol Hepatol. 1994;9(6):654-658.

23. El Azzouzi D. Primary intrathoracic gastric volvulus in the neonatal period: a differential diagnosis of esophageal atresia. Pan Afr Med J. 2014; 17:261.

24. Nosher JL, Campbel WL, Seaman WB. The clinical significance of cervical esophageal and hypopharyngeal webs. Radiology. 1975;117(1): 45-47.

25. Bredenkamp JK, Castro DJ, Mickel RA. Importance of iron repletion in the management of plummer-vinson syndrome. Ann Otol Rhinol Laryngol. 1990;99(1):51-54. 
26. Dantas RO, Villanova MG. Esophageal motility impairment in plummer-vinson syndrome. Correction by iron treatment. Dig Dis Sci. 1993;38(5):968-971.

27. Dantas RO. Iron deficiency and dysphagia. Am J Gastroenterol. 1999;94(10):3072-3073.

28. Chisholm M, Ardran GM, Callender ST, Wright R. Iron deficiency and autoimmunity in post-cricoid webs. Q J Med. 1971;40(159):421-433.

29. Chisholm M. The association between webs, iron and post-cricoid carcinoma. Postgrad Med J. 1974;50(582):215-219.

30. Adlington P, Leedham P, Smith P. The place of iron deficiency in the paterson-brown kelly syndrome. J Laryngol Otol. 1973;87(9):845-859.

31. Wynder EL, Hultberg S, Jacobsson F, Bross IJ. Environmental factors in cancer of the upper alimentary tract; a Swedish study with special reference to plummer-vinson (paterson-kelly) syndrome. Cancer. 1957;10(3): 470-487.

32. Thakur K, Tomar SK, Singh AK, Mandal S, Arora S. Riboflavin and health: a review of recent human research. Crit Rev Food Sci Nutr. 2017:57(17):3650-3660.

33. Jacobs A, Cavill IA. Pyridoxine and riboflavin status in the patersonkelly syndrome. Br J Haematol. 1968;14(2):153-160.

34. Makharia GK, Nandi B, Garg PK, Tandon RK. Plummer vinson syndrome: unusual features. Indian J Gastroenterol. 2002;21(2):74-75.

35. Dejmkova H, Pavelka K. An unusual clinical manifestation of secondary Sjogren's syndrome and concomitant paterson-kelly syndrome. Clin Rheumatol. 1994;13(2):305-308.

36. Mnif L, Amouri A, Tahri N. Celiac disease presenting as plummervinson syndrome. Tunis Med. 2010;88(11):858.

37. Sinha SK, Nain CK, Udawat HP, et al. Cervical esophageal web and celiac disease. J Gastroenterol Hepatol. 2008;23(7 Pt 1):1149-1152.

38. Dickey W, McConnell B. Celiac disease presenting as the paterson-brown kelly (plummer-vinson) syndrome. Am J Gastroenterol. 1999;94(2):527-529.

39. Dagg JH, Goldberg A, Gibbs WN, Anderson JR. Detection of latent pernicious anaemia in iron-deficiency anaemia. $\mathrm{Br}$ Med $\mathrm{J}$. 1966;2(5514):619-621.

40. Beveridge BR, Bannerman RM, Evanson JM, Witts LJ. Hypochronic anemia. A retrospective study and follow-up 378 in patients. $Q \mathrm{~J} \mathrm{Med}$. 1965;34:145-161.

41. Medrano M. Dysphagia in a patient with rheumatoid arthritis and iron deficiency anemia. MedGenMed. 2002;4(3):10.

42. Dagg JH, Goldberg A, Anderson JR, Beck JS, Gray KG. Autoimmunity in iron deficiency anemia. Br Med J. 1964;1(5394):1349-1350.

43. Geerlings SE, Statius van Eps LW. Pathogenesis and consequences of plummer-vinson syndrome. Clin Investig. 1992;70(8):629-630.

44. Atmatzidis K, Papaziogas B, Pavlidis T, Mirelis C, Papaziogas T. Plummer-vinson syndrome. Dis Esophagus. 2003;16:154-157.

45. Okamura H, Tsutsumi S, Inaki S, Mori T. Esophageal web in plummervinson syndrome. Laryngoscope. 1988;98(9):994-998.

46. Jones RF. The paterson-brown kelly syndrome. Its relationship to iron deficiency and postcricoid carcinoma. I. J Laryngol Otol. 1961;75:529-543.

47. Miranda AL, Dantas RO. Esophageal contractions and oropharyngeal and esophageal transits in patients with iron deficiency anemia. Am J Gastroenterol. 2003;98(5):1000-1004.
48. Entwistle CC, Jacobs A. Histological findings in the paterson-kelly syndrome. J Clin Pathol. 1965;18(4):408-413.

49. Jacobs A. The buccal mucosa in anaemia. J Clin Pathol. 1960;13(6): 463-468.

50. Jacobs A, Kilpatrick GS. The paterson-kelly syndrome. $B r$ Med J. 1964; 2:79-82.

51. Butori M, Mahmoudi S, Dugelay-Ecochard E, et al. Plummer-vinson syndrome in children. J Pediatr Gastroenterol Nutr. 2015;61(5): $547-552$.

52. Richards SH, Kilby D, Shaw JD. Post-cricoid carcinoma and the paterson-kelly syndrome. J Laryngol Otol. 1971;85:141-152.

53. Logan JS. A review of the plummer-vinson stricture of the cervical oesophagus. Ulster Med J. 1978;47(Suppl 2):1-14.

54. Atkinson M, Ferguson R. Fibreoptic endoscopic palliative intubation of inoperable oesophagogastric neoplasms. Br Med J. 1977; 1(6056):266-267.

55. Sinha V, Prajapati B, George A, Gupta D. A case study of plummer-vinson syndrome. Indian J Otolaryngol Head Neck Surg. 2006;58(4):391-392.

56. Grant PD, Morgan DE, Scholz FJ, Canon CL. Pharyngeal dysphagia: what the radiologist needs to know. Curr Probl Diagn Radiol. 2009;38(1):17-32.

57. Ekberg O, Nylander G. Cineradiography of the pharyngeal stage of deglutition in 250 patients with dysphagia. $\mathrm{Br} J$ Radiol. 1982;55(652):258-262.

58. Ekberg O. Cervical oesophageal webs in patients with dysphagia. Clin Radiol. 1981;32(6):633-641.

59. Ekberg O, Nylander G. Webs and web-like formations in the pharynx and cervical esophagus. Diagn Imaging. 1983;52(1):10-18.

60. Waldenstrom J, Kjellberg SR. The roentgenological diagnosis of sideropenic dysphagia (plummer-vinson syndrome). Acta Radiologica. 1939;20:618-638.

61. Shauffer IA, Phillips HE, Sequeira J. The jet phenomenon: a manifestation of esophageal web. AJR Am J Roentgenol. 1977;129(4):747-748.

62. DeLoughery TG. Iron deficiency anemia. Med Clin NorthAm. 2017;101(2): 319-332.

63. Lopez A, Cacoub P, Macdougall IC, Peyrin-Biroulet L. Iron deficiency anaemia. Lancet. 2016;387(10021):907-916.

64. Cook JD. Diagnosis and management of iron-deficiency anaemia. Best Pract Res Clin Haematol. 2005;18(2):319-332.

65. Sugiura Y, Nakagawa M, Hashizume T, Nemoto E, Kaseda S. Iron supplementation improved dysphagia related to plummer-vinson syndrome. Keio J Med. 2015;64(3):48-50.

66. Tahara T, Shibata T, Okubo M, et al. A case of plummer-vinson syndrome showing rapid improvement of dysphagia and esophageal web after two weeks of iron therapy. Case Rep Gastroenterol. 2014;8(2):211-215.

67. Yasawy MI. Treatment of plummer-vinson syndrome with savarygilliard dilatation. Saudi Med J. 2004;25(4):524-526.

68. Nishitani M, Matsuda M, Arihara F, Sakai A, Noda Y. Electroincision for hypopharyngoesophageal stricture caused by plummer-vinson syndrome. Gastrointest Endosc. 2016;84(5):849-850.

69. Watts JM. The importance of the plummer-vinson syndrome in the aetiology of carcinoma of the upper gastrointestinal tract. Postgrad Med J. 1961;37:523-533.
Journal of Blood Medicine

\section{Publish your work in this journal}

The Journal of Blood Medicine is an international, peer-reviewed, open access, online journal publishing laboratory, experimental and clinical aspects of all aspect pertaining to blood based medicine including but not limited to: Transfusion Medicine; Blood collection, Donor issues, Transmittable diseases, and Blood banking logistics; Immunohematology; Artificial and alternative

\section{Dovepress}

blood based therapeutics; Hematology; Biotechnology/nanotechnology of blood related medicine; Legal aspects of blood medicine; Historical perspectives. The manuscript management system is completely online and includes a very quick and fair peer-review system. Visit http://www.dovepress.com/ testimonials.php to read real quotes from published authors. 